\title{
A fala fora de lugar: Testemunho, Resto, tempo e linguagem em Ricardo Piglia
}

\author{
THE SPEECH MISPLACED: TESTIMONY, REMNANTS, \\ time and language IN RICARDO PIGlia \\ Rafaela Scardino
}

Universidade Federal do Espírito Santo

Vitória, ES, Brasil

Palavras-chave: Testemunho; resto; tempo; linguagem; Ricardo Piglia.
Keywords: Testimony; remnants; time; language; Ricardo Piglia.

Palabras clave: Testimonio; resto; tiempo; lenguaje; Ricardo Piglia.

\section{Resumo}

Um pensamento dedicado ao problema do testemunho defronta, náo raro, questóes relacionadas, intrinsecamente, a tempo e linguagem. Tais questóes surgem no debate como conceitos de larga abordagem, uma vez que acompanham, por milênios, o desenvolvimento das meditaçóes humanas. Giorgio Agamben, em parte significativa de sua obra, insere, no debate acerca do testemunho, um relevante ponto de discussão: o resto. Buscando refletir sobre esses aspectos, em especial sobre testemunho, resto, tempo e linguagem, propomo-nos a analisar o romance $A$ cidade ausente, de Ricardo Piglia, de modo a investigar, na narrativa do escritor argentino, os mecanismos textuais que interrogam as possibilidades (e impossibilidades) de constituiçáo da experiência na contemporaneidade.

\section{Abstract}

A thought devoted to the problem of testimony is often obliged to face questions related to time and language. Such issues arise in the debate as concepts of a broader approach, since they are attached to the development of human meditations. Giorgio Agamben, in a significant part of his work, inserts, in the debate about testimony, a relevant point of discussion: the remnant. Seeking to on these aspects, particularly on testimony, remnants, time and language, we propose an analysis of the novel The absent city, by Ricardo Piglia, to investigate, in his narratives, the textual mechanisms that interrogate the

\section{Resumen}

Un pensamiento dedicado al problema del testimonio enfrenta, a menudo, problemas relacionados al tiempo y el lenguaje. Estas cuestiones surgen en el debate como conceptos de largo enfoque, una vez que acompañan el desarrollo de las meditaciones humanas. Giorgio Agamben, en importante parte de su obra, inserta en el debate sobre el testigo, un punto relevante de la discusión: el resto. Buscando reflexionar sobre estos aspectos, especialmente sobre el testimonio, el resto, el tiempo y el lenguaje, nos proponemos analizar la novela $L a$ ciudad ausente, de Ricardo Piglia, de modo a investigar, en la narra- 
possibilities (and impossibilities) of constitution of experience in contemporaneity. tiva del escritor argentino, los mecanismos textuales que cuestionan las posibilidades (e imposibilidades) de la constitución de la experiencia en la contemporaneidad.

\section{Testemunho}

O nascimento da História, na Grécia, está ligado à instância da verdade do discurso e, para tanto, é fundamental a presença do outro, que comparece, muitas vezes, como testemunha. Jeanne Marie Gagnebin nos diz que

Heródoto fala daquilo que ele mesmo viu, ou daquilo de que ouviu falar por outros; ele privilegia a palavra da testemunha, ${ }^{1}$ a sua própria ou a de outrem. Inúmeras vezes, no decorrer de sua narrativa, o nosso viajante menciona as suas "fontes", se ele mesmo viu o que conta ou se só ouviu falar e, neste caso, se o "informante" tinha visto, ele mesmo, ou só ouvido falar.*

Vemos que, no texto de Heródoto, conforme nos fala Gagnebin, o relato nasce da possibilidade de experiência, do próprio sujeito que narra, ou de outro. Ou ainda, da experiência transmitida pela fala, por ouvir contar (narrar) alguém que a tivesse acumulado. A testemunha, esse outro trazido ao discurso, tem uma dimensão ética, por ser o outro que permite que se compartilhe a experiência, que só se completa na transmissão.

Em O que resta de Auschwitz, Agamben traz à discussão, como elemento fundamental, o conceito teológico-messiânico de resto, que será desenvolvido em livro posterior, $O$ tempo que resta, dedicado à compreensão do tempo messiânico em Paulo (e suas implicaçóes para a concepção do Jetztzeit benjaminiano). Neste texto, Agamben retoma o conceito, explicitando que resto "não é, portanto, nem o todo nem uma parte do todo, mas ele significa a impossibilidade para a parte e o todo de coincidirem, ao mesmo tempo, consigo mesmos e entre si”.*

O termo resto aparece já no Antigo Testamento, em textos proféticos que afirmam que apenas o resto de Israel se salvará, não o

\footnotetext{
${ }^{1}$ Segundo Giorgio Agamben, "Histor é, na origem, a testemunha ocular, aquele que viu” (AGAMBEN, Giorgio. Infância e História. Belo Horizonte: UFMG, 2005: 114).
}

* (GAGNEBIN, Jeane Marie. Sete aulas sobre linguagem memória e história. Rio de Janeira: Imago, 1997: 16.)

* (AGAMBEN, Giorgio. Le temps qui reste. Paris: Payot \& Rivage, 2004: 97. .) 
* (Apud AGAMBEN, Giorgio. O que resta de Auschwitz. São Paulo: Boitempo, 2008: 161.)

* (AGAMBEN, Giorgio. O que resta de Auschwitz. São Paulo: Boitempo, 2008: 162. Grifos do autor.)

* (AGAMBEN, Giorgio. O que resta de Auschwitz. São Paulo: Boitempo, 2008: 43.) todo de seu povo, como em Is. 10, 22: "Mesmo que o teu povo, ó Israel, seja como a areia do mar, só o resto se salvará" * No entanto, resto não significa aqui uma porção do povo de Israel, mas “ a consistência que Israel assume no ponto em que é posto em relação imediata com o éschaton, com o evento messiânico ou com a eleiçâo".* Também em Paulo aparece a noção do resto relacionada à salvação: o "tempo de agora" (ho num kairos), tempo messiânico, torna-se resto. ${ }^{2}$

Ligada, desde os textos de Heródoto, à legitimação do relato, a testemunha pode ocupar a posição de resto, pois é, segundo Agamben, aquele sujeito que deverá falar na impossibilidade de falar, falará por um outro, ausente, de quem foi retirada a fala. Analisando os textos de Primo Levi, o filósofo debruça-se sobre a figura do muçulmano, que, segundo Levi, seria a única testemunha integral, mas que, justamente, não pode falar: “As 'verdadeiras' testemunhas, as 'testemunhas integrais' são as que não testemunharam, nem teriam podido fazê-lo. São os que 'tocaram o fundo', os muçulmanos, os submersos". * Assim os descreve Primo Levi, em É isto um homem?:

A história - ou melhor, a não-história - de todos os "muçulmanos" que vão para o gás é sempre a mesma: simplesmente, acompanharam a descida até o fim, como os arroios que vão até o mar. Uma vez dentro do campo, ou por causa de sua intrínseca incapacidade, ou por azar, ou por um banal acidente qualquer, eles foram esmagados antes de conseguir adaptar-se; ficaram para trás, nem começaram a aprender o alemão e perceber alguma coisa no emaranhado infernal de leis e proibiçóes, a não ser quando seu corpo já desmoronara e nada mais poderia salvá-los da seleção ou da morte por esgotamento. A sua vida é curta, mas seu número é imenso; são eles, os "muçulmanos", os submersos, são eles a força do campo: a multidão anônima, continuamente renovada e sempre igual, dos não-homens que marcham e se esforçam em silêncio; já se apagou neles a centelha divina, já estão tão vazios, que nem podem realmente sofrer.

${ }^{2}$ Cf. AGAMBEN, Giorgio. O que resta de Auschwitz, São Paulo: Boitempo, 2008: 162. É importante ressaltar que, para Paulo, o tempo messiânico, "tempo de agora" ( ho nun kairos) compreende as duas partes do evento messiânico: a ressurreição do messias e a parousia, sua segunda vinda. Daí, escreve Agamben, a "tensão paradoxal entre um 'jâ e um 'ainda não' que define, tradicionalmente, a concepção paulínica da salvação" (AGAMBEN, Giorgio. Le temps qui reste. Paris: Payot \& Rivage, 2004: 122), pois o tempo messiânico é um tempo cindido. A parousia, que, em grego, significa apenas presença, "não indica nem um complemento, que se adicionaria a qualquer coisa para completá-la, nem um suplemento, que se adicionaria posteriormente sem jamais chegar a atingir sua realizaçáo" (AGAMBEN, G. Le temps qui reste, op. cit. p. 125). Paulo se serve dessa noção para designar a estrutura uni-dual íntima do evento messiânico. A própria constituição do evento messianico é, portanto, aquela do resto, da não coincidência. 
Hesita-se em chamá-los vivos; hesita-se em chamar "morte" à sua morte, que eles já nem temem, porque estão esgotados demais para poder compreendê-la.

Eles povoam minha memória com sua presença sem rosto, e se eu pudesse concentrar numa imagem todo o mal do nosso tempo escolheria essa imagem que me é familiar: um homem macilento, cabisbaixo, de ombros curvados, em cujo rosto, em cujo olhar, náo se possa ler o menor pensamento.*

Quem fala, portanto, o faz a partir de uma falta, de um dizer ausente, como o do muçulmano. Pois a testemunha integral do horror só pode ser aquela que o experimentou plenamente, em todas as suas consequências, e desta é retirada a possibilidade de fala, tendo em vista que "a língua, para testemunhar, deve ceder lugar a uma não-língua, mostrar a impossibilidade de testemunhar”.*

Dessa forma, a testemunha não pode testemunhar senão partindo de uma ausência, de um hiato que é, também, o da palavra poética:

[A] palavra poética é aquela que se situa, de cada vez, na posição de resto, e pode, dessa maneira, dar testemunho. Os poetas - as testemunhas - fundam a língua como o que resta, o que sobrevive em ato à possibilidade - ou à impossibilidade - de falar.*

Agamben se refere ao poeta como o auctor por excelência. É interessante notar, no breve percurso etimológico traçado pelo filósofo, a constituição da palavra "auctor" como testemunha. Segundo Agamben, a palavra latina "auctor", que dará origem ao moderno termo "autor", "significa originariamente quem intervém no ato de um menor [...] para lhe conferir o complemento de validade de que necessita”.* Dentre suas acepçóes, está a de testemunha,

enquanto seu testemunho pressupóe sempre algo [...] que lhe preexiste, e cuja realidade e força devem ser convalidadas ou certificadas. [...] O testemunho sempre é, pois, um ato de "autor", implicando sempre uma dualidade essencial, em que são integradas e passam a valer uma insuficiência ou uma incapacidade.*

Tal convalidação e complementação ficam patentes na acepção de autor como criador, pois

todo criador é sempre co-criador, todo autor, coautor. E assim como o ato do auctor completa o do incapaz, dá força de prova ao que, em si, falta, e vida ao que por si só não poderia viver, pode-se afirmar, ao contrário, que é o ato imperfeito ou a incapacidade que
* (Apud AGAMBEN, Giorgio. O que resta de Auschwitz. São Paulo: Boitempo, 2008: 51-52.)

* (AGAMBEN, Giorgio. O que resta de Auschwitz. São Paulo: Boitempo, 2008: 48.)

* (AGAMBEN, Giorgio. O que resta de Auschwitz. São Paulo: Boitempo, 2008: 160.)

* (AGAMBEN, Giorgio. O que resta de Auschwitz. São Paulo: Boitempo, 2008: 149.)

* (AGAMBEN, Giorgio. O que resta de Auschwitz. São Paulo: Boitempo, 2008: 150.) 
* (AGAMBEN, Giorgio. O que resta de Auschwitz. São Paulo: Boitempo, 2008: 151.)

* (PIGLIA, Ricardo. A cidade ausente. São Paulo: Iluminuras, 1997: 35.)

* (PIGLIA, Ricardo. A cidade ausente. São Paulo: Iluminuras, 1997: 115-116.) o precedem e que ele vem a integrar que dá sentido ao ato ou à palavra do auctor-testemunha.*

No romance $A$ cidade ausente, do argentino Ricardo Piglia, o protagonista Júnior busca desvendar a história de criação e funcionamento de uma máquina geradora de relatos que é mantida em museu pelas forças estatais. Tal invenção, criada pelos personagens Russo (ou Engenheiro) e Macedonio Fernández a partir da memória da mulher morta deste último, Elena, deveria, a princípio, ser uma máquina tradutora. Um erro em sua configuração inicial, no entanto, gerou uma máquina "transformadora de histórias".* Assim, ao inserir-se o conto "William Wilson", de Poe, a máquina gera o relato "Stephen Stevensen". Em uma de suas conversas com Júnior, no entanto, Russo, afirma que não poderia havê-la criado ex nibilo, que era preciso um mecanismo anterior: "Inventar uma máquina é fácil, se a pessoa conseguir modificar as peças de um mecanismo anterior. As possibilidades de transformar aquilo que já existe numa outra coisa são infinitas. Eu não poderia fazer nada a partir do nada".* O ato de criação de Macedonio e de Russo é, portanto, um ato de co-criação, pois partem não apenas de um mecanismo anterior, como se disse, mas de uma memória anterior - a memória de Elena inscrita nos nódulos brancos ${ }^{3}$ - para criar uma máquina que é, também, repositório da memória coletiva.

Lembremos que a origem dos relatos da máquina é, inicialmente, um erro, um ato incompleto, que necessita de convalidação:

Júnior começava a entender. No início a máquina se engana. O erro é o primeiro princípio. A máquina desagrega "espontaneamente" os elementos do conto de Poe e os transforma nos núcleos potenciais da ficção. Assim tinha surgido a trama inicial. $\mathrm{O}$ mito da origem. Todas as histórias vinham daí. O sentido futuro do que estava se passando dependia desse relato sobre o outro e o porvir. O real estava

\footnotetext{
${ }^{3}$ Título de um dos capítulos de $A$ cidade ausente, os "nódulos brancos" são definidos por um personagem, Dr. Arana, como "mitos", que "definem a gramática da experiência. Tudo o que os linguistas nos ensinaram sobre a linguagem também está no coração da matéria viva. $\mathrm{O}$ código genético e o código verbal apresentam o mesmo padrăo. Chamamos a isso nódulos brancos" (PIGLIA, Ricardo. A cidade ausente. São Paulo: Iluminuras, 1997: 59). Em outro momento, o narrador deste capítulo diz que: "Os nódulos brancos tinham sido, na origem, marcas nos ossos. O mapa de uma linguagem cega comum a todos os seres vivos. [...] A partir desses núcleos primitivos tinham se desenvolvido ao longo dos séculos todas as línguas do mundo. [...] No passado todos tínhamos entendido o sentido de todas as palavras, os nódulos brancos estavam gravados no corpo como uma memória coletiva” (PIGLIA, Ricardo. A cidade ausente. São Paulo: Iluminuras, 1997: 66-67).
} 
sendo definido pelo possível (e não pelo ser). A oposição verdade/ mentira devia ser substituída pela oposiçáo possível/impossível.*

Neste momento, gostaríamos de meditar acerca de um novo conceito, retirado da obra de Giorgio Agamben: o "como não" ( hōs $m \bar{e}$ ) paulínico. Em sua primeira epístola aos Coríntios (I Cor 7, 29-32), Paulo escreve sobre o chamado messiânico:

Isto, porém, vos digo, irmãos: o tempo se contraiu, o resto é que aqueles que têm mulher sejam como não a tendo (hōs $m \bar{e})$; e aqueles que choram, como náo chorando; e aqueles que têm alegria, como não a tendo; e aqueles que compram, como não possuindo; e aqueles que usam o mundo, como náo abusando. Pois ela passa, a imagem deste mundo. Eu desejo que vós não tenhais preocupaçóes.*

O "como não" (hōs mē) está ligado à vocação, ao chamado messiânico (klèsis), que submete todos os estados mundanos e jurídicos à relação com o evento messiânico. A vocação messiânica

não é um direito, não constitui uma identidade: é um poder genérico que deve ser utilizado sem ser jamais apropriado. Ser messiânico, viver no messias significa despossuir, na forma do como não, toda propriedade jurídico-factual [...]; mas esta despossessão não funda uma nova identidade, e a "nova criatura" não é senão o uso e a vocação messiânica da antiga.*

Para Agamben, a fórmula da vida messiânica é esse "como não" ( hōs $m \bar{e})$ paulínico, "a revocação de toda vocação".* Segundo o autor, o "como não" ( hōs $m \bar{e})$ coloca um determinado termo em tensão consigo próprio, e não em relação a outro; da mesma forma que a vocação messiânica coloca uma determinada condição tensionada em relação a si mesma, sem alterar sua forma. Ou seja, Paulo lança a negação de um termo sobre si mesmo. Por isso, a estrutura "como não", pois

a tensão messiânica não se direciona a um outro [...]. O apóstolo não diz: "aqueles que choram como se rissem", nem "aqueles que choram como (quer dizer =) aqueles que não choram", mas "aqueles que choram como náo chorando”. Segundo o princípio da klēsis messiânica, uma condição factual determinada é posta em relação consigo mesma [...] e, de certa maneira, reconvocada e recolocada em questão sem por isso ser alterada em sua forma.*

$\mathrm{O}$ erro que funda o funcionamento da máquina de $A$ cidade ausente inscreve, nela e em seus relatos, o "como não" (hōs $m \bar{e})$ : a máquina narra o "William Wilson" como não sendo um conto de Poe, instaura entre o texto e ele mesmo uma não coincidência, de
* (PIGLIA, Ricardo. A cidade ausente. São Paulo: Iluminuras, 1997: 82.)

* (Apud AGAMBEN, Giorgio. Le temps qui reste. Paris: Payot \& Rivage, 2004: 45-46.)

* (AGAMBEN, Giorgio. Le temps qui reste. Paris: Payot \& Rivage, 2004: 50-51.)a

* (AGAMBEN, Giorgio. Le temps qui reste. Paris: Payot \& Rivage, 2004: 46.)

* (AGAMBEN, Giorgio. Le temps qui reste. Paris: Payot \& Rivage, 2004: 47-48.) 
* (AGAMBEN, Giorgio. O que resta de Auschwitz. São Paulo: Boitempo, 2008: 160.)
* (AGAMBEN, Giorgio. O que resta de Auschwitz. São Paulo: Boitempo, 2008: 146. Grifos do autor.) onde nasce o "Steven Stevenson", um dizer novo (mas co-criado) que é testemunho do "William Wilson", que o insere na cisão entre o possível e o impossível. A própria máquina está instalada nessa "divisão da divisão", 4 pois é criada a partir da memória da mulher morta de Macedonio, mas não coincide com ela e não pode, sequer, morrer. O "como não" funciona, então, como o instaurador da não coincidência: "Steven Stevenson" é o "William Wilson" como não "William Wilson"; a máquina é Elena como não Elena.

\section{Resto}

O poeta (de modo geral, o escritor) é aquele que vive a língua como resto, como testemunho, como algo fora do arquivo. Ele está "na própria língua na posição dos que a perderam, [situa-se] em uma língua viva como se fosse morta, ou em uma língua morta como se fosse viva - em todo caso, tanto fora do arquivo, quanto fora do corpus do já-dito".*

A língua do testemunho deve colocar-se, portanto, na posição de resto, em contraponto ao arquivo,

que designa o sistema das relaçóes entre o dentro e o fora da langue, entre o dizível e o não dizível em toda língua - ou seja, entre uma potência de dizer e a sua existência, entre uma possibilidade e uma impossibilidade de dizer. Pensar em uma potência em ato enquanto potência, ou seja, pensar a enunciação no plano da langue equivale a inscrever na possibilidade uma cisão que a divide em uma possibilidade e uma impossibilidade, em uma potência e uma impotência, e, nessa cisão, situar um sujeito.*

Propomos que tal sujeito, situado na cisão entre a potência e a impotência de dizer, corresponderia, nas obras de Piglia, a uma instância organizadora dos diversos discursos textuais, das diversas vozes que compóem os enunciados. Tal instância, que se apresentaria como resto, como "divisão da divisão", organiza não apenas as vozes narrativas, os relatos (dos personagens, da máquina), mas inclusive os vazios textuais, as ausências que compóem esses textos. Tal instância não se inscreve como mais uma voz textual como os narradores, os personagens ou mesmo a máquina -, mas como uma ausência significante: o "como não" paulínico, aquilo que impede a coincidência e instaura o resto.

\footnotetext{
${ }^{4}$ Cf. AGAMBEN, Giorgio. Le temps qui reste. Paris: Payot \& Rivage, 2004: 9495: "Em Paulo, não existe nem princípio nem fim, existe somente o corte de Apeles, a divisão da divisão - e depois existe um resto".
} 
É interessante apontar para a cisão, explicitando que não é um vazio, mas uma divisão prenhe de sentido. Assim como o escuro "não é [...] um conceito privativo, a simples ausência da luz, algo como uma não-visão, mas o resultado da atividade das off-cells, um produto de nossa retina", ${ }^{*}$ a cisão é o lugar de instauração do sujeito e, portanto, da possibilidade de dizer $e u$, diante da impossibilidade de conceder à enunciação desse eu uma referência unívoca.

A instância organizadora, situada nessa cisão geratriz, instaura um outro tempo da narrativa, que acreditamos corresponder ao Jetzteit benjaminiano, o tempo propício para a construção de uma história que se opusesse àquela que habita um "tempo homogêneo e vazio",* o historicismo. "Realmente histórico", escreve Agamben, "é aquilo que cumpre o tempo não na direção do futuro, nem simplesmente na direção do passado, mas no ato de exceder um meio".* Ou seja, realmente histórico é o tempo que inscreve o resto no presente.

Podemos aproximar o tempo do historicismo daquele que Émile Benveniste define como sendo o da enunciação histórica, que apresenta os fatos numa sucessão temporal dominada pelo passado, sem a irrupção do presente e sem nenhum gesto de autor. $\mathrm{O}$ tempo do discurso, por sua vez, é o da instauração do presente, que se dá sempre num "tempo-de-agora", em que um sujeito mobiliza a língua, apropriando-se dela para dizer $e u$, um $e u$ que é "a cada vez um ato novo" de enunciação.* O tempo de tal instância, portanto, é o tempo da inscrição "autobiográfica", que coloca os termos em tensão consigo mesmos, mas que é, também, limiar para a propositividade, para que se coloquem em movimento novas formas de leitura dos textos, novas formas de se apropriar da tradição. É esta instância, ainda, o que define a consistência da narrativa, sem coincidir com nenhuma de suas partes linguisticamente inscritas. Como um resto, está entre o que se manifesta e o que não se manifesta (linguisticamente); da mesma forma que o testemunho, ocupa o limiar entre a fala e a náo fala. Seria, portanto, uma metamáquina, que não produz relatos, mas relaçóes entre relatos.

\section{Tempo}

O tempo messiânico é chamado por Paulo de "tempo de agora" (ho nun kairos). A escolha pela palavra grega kairos, muitas vezes traduzida como instante, está ligada ao fato de que a vivência do kairos
* (AGAMBEN, Giorgio. $O$ que é o contemporâneo? e outros ensaios. Chapecó, SC: Argos, 2009: 63.)

* (BENJAMIN, Walter. Magia e técnica, arte e política: ensaios sobre literatura e história da cultura. São Paulo: Brasiliense, 1994: 229.)

* (AGAMBEN, Giorgio. O que resta de Auschwitz. São Paulo: Boitempo, 2008: 158.)

* (BENVENISTE, Émile. Problemas de linguística geral II. Campinas: Pontes Editores, 1989: 68.) 
* (BENJAMIN, Walter. Magia e técnica, arte e política: ensaios sobre literatura e história da cultura. São Paulo: Brasiliense, 1994: 232.)

* (AGAMBEN, Giorgio. Le temps qui reste. Paris: Payot \& Rivage, 2004: 119. Grifos do autor.) pressupõe que não haja outro tempo, impedindo, assim, a intromissão do "tempo profano" (chronos) na experiência messiânica. É o tempo que se contraiu, após a vocação messiânica, instaurando, portanto, o resto (como vimos na descrição do "como não", anteriormente). Parece-nos importante destacar as similaridades entre o "tempo de agora" ( ho nun kairos) paulínico e o "tempo-de-agora" (Jetztzeit) benjaminiano. 'Também o Jetztzeité uma contração: "tempode-agora", "enquanto modelo do tempo messiânico, resume a história de toda a humanidade numa prodigiosa abreviação".* Incrustado de "estilhaços do tempo messiânico", o "tempo-de-agora" interrompe a continuidade histórica, seu fluxo ininterrupto de "progressismo" e relatos sobre os vencedores. É o tempo que insere no continuum do historicismo a rememoração dos vencidos, dos oprimidos, para redimi-los. É o tempo da redenção do tempo.

O tempo messiânico, assinala Giorgio Agamben, "tem a capacidade singular de colocar em relação consigo mesmo todo instante do passado", ou seja, é a apropriação messiânica de um evento do passado que o coloca não apenas em relação consigo mesmo, mas também com o agora, retirando-o do fluxo vazio do historicismo e inserindo-o na história, na experiência. Para definir este tempo, o filósofo recorre ao conceito linguístico de “tempo operativo", desenvolvido por Gustave Guillaume, quem afirma que as representaçóes espaciais do tempo, oferecidas pela gramática, nos dão a ver o tempo sempre pronto, construído, sem jamais incluir em si mesmas o tempo em sua construção no pensamento, pois todas as operaçóes mentais, afirma o linguista, levam uma determinada quantidade de tempo para se concretizarem, tempo este que denomina "tempo operativo". Trazendo o conceito para sua discussão sobre o tempo messiânico, Agamben afirma que, assim como o tempo operativo, o tempo messiânico é "o tempo que o tempo leva para terminar", que não se situa senão no presente, mas deslocado em relação a ele.

\footnotetext{
${ }^{5}$ Cf. AGAMBEN, Giorgio. Le temps qui reste. Paris: Payot \& Rivage, 2004: 112. O tempo profano, ao qual Paulo se refere pelo termo chronos, é aquele anterior à contração do tempo, que tem início com o evento messiânico. É o tempo, portanto, que decorre entre a criaçáo do mundo e o evento messiânico (a ressurreição do messias).

${ }^{6}$ Utilizamos tradução de Jeanne Marie Gagnebin e Marcos Lutz Müller, além da tradução feita pelo próprio Agamben, quem, a respeito da coincidência entre os termos, afirma que "todo o vocabulário das teses parece marcado por um selo paulínico” (AGAMBEN, Giorgio. Le temps qui reste. Paris: Payot \& Rivage, 2004: 241).
} 
Questões semelhantes são colocadas por Benveniste quando trata do "tempo crônico" e do "tempo linguístico". O tempo crônico seria aquele dos acontecimentos, "congelado na história",* e que poderíamos aproximar do continuum de que fala Benjamin. É o tempo que conseguimos representar, em nossa vida cotidiana, utilizando-nos, por exemplo, de calendários: "O tempo crônico fixado num calendário é estranho ao tempo vivido e não pode coincidir com ele", pois, "pelo próprio fato de ser objetivo, propóe medidas e divisóes uniformes em que se alojam os acontecimentos, mas estes não coincidem com as categorias próprias da experiência humana do tempo".* O tempo linguístico, por sua vez, está ligado ao exercício da fala, e deve organizar-se como função discursiva:

Este tempo tem seu centro - um centro ao mesmo tempo gerador e axial - no presente da instância da fala. Cada vez que um locutor emprega a forma gramatical do "presente" (ou uma forma equivalente), ele situa o acontecimento como contemporâneo da instância do discurso que o menciona. É evidente que este presente, na medida em que é função de discurso, não pode ser localizado em uma divisão particular do tempo crônico, porque ele admite todas as divisóes e não se refere a nenhuma em particular.*

Por fim, convocamos a palavra de Hannah Arendt, ${ }^{7}$ para quem o presente, esta lacuna entre o futuro e o passado, deve ser descoberto e pavimentado a cada vez que é vivido. Tal colocação ligase à compreensão do presente como "tempo que resta", pois deve ser refundado a cada instante, sem a intromissão do passado ou do futuro, que serão ressignificados pelo presente, agindo da mesma forma que a "língua como resto" - a língua literária -, que recria e reorganiza a tradição, conferindo-lhe novos significados a cada nova enunciação.

\section{Linguagem}

A língua que se situa entre a possibilidade e a impossibilidade de dizer, isto é, a língua como resto, encontra ressonâncias na escrita de Ricardo Piglia. Ao apontar para a impossibilidade de representar a dor e a experiência (em especial a experiência da dor), encontramos em sua obra a afirmação de que é preciso levar a linguagem a seu limite, ou seja, impedi-la de coincidir consigo mesma, para

${ }^{7}$ Cf. ARENDT, Hannah. Entre o passado e o futuro. São Paulo: Perspectiva, 2011 : 39: "o homem na plena realidade de seu ser completo vive nessa lacuna temporal entre o passado e o futuro".
* (BENVENISTE, Émile. Problemas de linguística geral II. Campinas: Pontes Editores, 1989: 71.)

* (BENVENISTE, Émile. Problemas de linguística geral II. Campinas: Pontes Editores, 1989: 74.)

* (BENVENISTE, Émile. Problemas de linguística geral II. Campinas: Pontes Editores, 1989: 74-75.) 
* (PIGLIA, Ricardo. Uma proposta para o novo milênio. Lisboa, Buenos Aires: Coletivo Chão da Feira, 2012: 02.) que, nesse deslocamento, possa-se criar algo como um lugar para o sujeito. ${ }^{8}$ Para o escritor argentino,

a experiência do horror puro da repressão clandestina - uma experiência que frequentemente parece estar além da linguagem - talvez defina o nosso uso da linguagem e a nossa relação com a memória e, portanto, com o futuro e o sentido. Há um ponto extremo, um lugar - digamos - do qual parece impossível se aproximar com a linguagem. Como se a linguagem tivesse uma margem, como se a linguagem fosse um território com uma fronteira, após a qual está o silêncio. Como narrar o horror? Como transmitir a experiência do horror e não só informar sobre ele? Muitos escritores do século XX enfrentaram esta questão: Beckett, Kafka, Primo Levi, Anna Akhmátova, Marina Tsvetáieva, Paul Celan. A experiência dos campos de concentração, a experiência do gulag, a experiência do genocídio. A literatura prova que há acontecimentos que são muito difíceis, quase impossíveis, de transmitir: supóe uma relação nova com a linguagem dos limites.*

É interessante notar a relação que se estabelece entre futuro, memória e tradição, neste trecho de "Uma proposta para o novo milênio". A relação com as possibilidades presentes da língua colocam em xeque o futuro, para o qual será preciso criar um sentido, e a tradição - representada pelos escritores nomeados -, com a qual deve-se estabelecer relaçóes de sentido. O sentido habita, portanto, o "tempo-de-agora”, com suas ressonâncias messiânicas (redentoras). Nesse tempo sempre deslocado, devemos situar a memória, ligada às possibilidades de fala de um eu que, como vimos, só existe no momento de sua enunciação. A memória, portanto, deve ser convocada ao momento da fala, da transmissão da experiência. Transmitir a experiência, e não apenas informar sobre ela, é, para Piglia, o que movimenta a obra dos importantes escritores convocados. Para transmitir a experiência, portanto, é preciso um gesto de autor que, sabemos, é sempre um gesto de co-criação. Como todo eu, pressupóe um $t u^{9}$ - um outro com quem estabelecer relaçóes, outro que possa

\footnotetext{
${ }^{8}$ Analisando o "Fragmento Teológico-político", de Benjamin, Jeanne Marie Gagnebin afirma que "é em nossas hesitaçóes, em nossas dúvidas, em nossos desvios, que pode ainda se insinuar o apelo messiânico, ali, enfim, onde renunciamos a tudo preencher para deixar que algo de outro possa dizer-se" (GAGNEBIN, J. M. História e narração em Walter Benjamin. São Paulo: Perspectiva, 2009: 98). É importante destacar que o apelo messiânico, em Benjamin, é o da redençáo dos oprimidos, esse outro excluído da história dos vencedores.

${ }^{9}$ Cf. BENVENISTE, Émile. Problemas de linguística geral I. Campinas: Pontes, 2005: 286: "A linguagem só é possível porque cada locutor se apresenta como sujeito, remetendo a ele mesmo como eu no seu discurso. Por isso, eu propóe
} 
dizer por nós, mas também outro que possa, ao criar sentido com nossa fala, traduzi-la em experiência. Outra questão importante é a afirmação da experiência do horror como ainda sendo experiência: talvez porque a experiência do homem tenha sido aquela do horror, ela se transfere, em $A$ cidade ausente, à máquina.

Giorgio Agamben, em Infancia e História, afirma que "todo discurso sobre a experiência deve partir atualmente da constatação de que ela não é mais algo que ainda nos seja dado fazer”. * No entanto, duas páginas à frente, escreve: "O que não significa que hoje não existam mais experiências. Mas estas se efetuam fora do homem".* Assim, como já apontado, a experiência, em $A$ cidade ausente, se transfere à máquina. A experiência aqui é deslocada não para a esfera de outro sujeito (humano), mas para algo inumano ou, de outro modo, para aquilo que - ainda não humano ou não mais humano - passa a constituir um repositório tanto para a experiência quanto para a memória, pois uma não se pode dar sem a outra. Esta experiência maquínica da memória não é, no entanto, a do arquivo. Os relatos da máquina têm consistência de resto: inserem-se, dessa maneira, na cisão entre a possibilidade e a impossibilidade de dizer.

A máquina, segundo Macedonio, "aprende à medida que vai narrando. Aprender quer dizer que ela lembra o que já fez e tem cada vez mais experiência. Não irá necessariamente fazer histórias cada vez mais belas, mas vai saber as histórias que já fez e talvez acabe por construir-lhes uma trama comum".* Como vemos, a máquina é repositório de experiência. Tal experiência, no entanto, que não busca produzir nem reproduzir "histórias cada vez mais belas", pode constituir, sim, uma experiência de dor. O primeiro relato da máquina transcrito no livro diz do horror e da dor, e também da impossibilidade de se constituir experiências somente com o corpo: a palavra torna-se, então, o fundamento da experiência.

Assim, no relato "A ilha", os habitantes de um território em que a linguagem é instável devem reconstruir a experiência a cada nova língua, "porque a gente sempre esquece a língua em que reteve as lembranças".* A cada nova língua falada, a anterior é esquecida; isso impossibilita o assentamento de uma tradição, pois "todas as

outra pessoa, aquela que, sendo embora exterior a "mim", torna-se meu eco - ao qual digo tu e que me diz tu. A polaridade das pessoas é na linguagem a condição fundamental, cujo processo de comunicação, de que partimos, é apenas uma consequência totalmente pragmática”.
* (AGAMBEN, Giorgio. Infância e História. Belo Horizonte: UFMG, 2005: 21.)

* (AGAMBEN, Giorgio. Infância e História. Belo Horizonte: UFMG, 2005: 23.)

* (PIGLIA, Ricardo. A cidade ausente. São Paulo: Iluminuras, 1997: 36.)

*(PIGLIA, Ricardo. A cidade ausente. São Paulo: Iluminuras, 1997: 98.) 
* (PIGLIA, Ricardo. A cidade ausente. São Paulo: Iluminuras, 1997: 101.)
* (PIGLIA, Ricardo. A cidade ausente. São Paulo: Iluminuras, 1997: 104.)
* (BENJAMIN, Walter. Escritos sobre mito e linguagem. São Paulo: Duas Cidades; Ed. 34, 2011: 55.)

* (BENJAMIN, Walter. Escritos sobre mito e linguagem. São Paulo: Duas Cidades; Ed. 34, 2011: 56.) obras-primas duram o que dura a língua em que foram escritas. Só o silêncio persiste, claro como a água, sempre igual a si mesmo".* Neste lugar, as noçóes espaciais são subvertidas, mudadas para noçóes temporais. $\mathrm{O}$ espaço perde sua estabilidade e fixidez, e passa a ser fluido como o tempo. Vejamos o texto:

Todas as tentativas de construir uma língua artificial foram perturbadas por uma experiência temporal da estrutura. Não conseguiram construir uma linguagem exterior à linguagem da ilha, porque náo podem imaginar um sistema de signos que persista sem mutaçôes. Se $a+b$ é igual $a c$, essa certeza serve apenas por um tempo, porque num espaço irregular de dois segundos $a$ já é - $a$ e a equação é outra. A evidência vale o que a proposiçáo demora para ser formulada. $\mathrm{Na}$ ilha, ser rápido é uma categoria da verdade. Nessas condiçôes, os linguistas da Área-Beta do Trinity College conseguiram o que parece impossível: quase fixam num paradigma lógico a forma incerta da realidade. Definiram um sistema de signos cuja notação se transforma com o tempo. Quer dizer, inventaram uma linguagem que mostra como é o mundo, mas que não permite nomeá-lo. Nós conseguimos estabelecer um campo unificado, disseram a Boas, agora só falta que a realidade incorpore alguma de nossas hipóteses à realidade.*

A prevalência de noçóes temporais instala a linguagem da ilha no "tempo como resto", pois, a afirmação de que "a evidência vale o que a proposiçáo demora para ser formulada", nos remete à proposição de que o lugar (utópico) da permanência da linguagem é o do tempo operativo, que não pode permanecer igual a si mesmo. A linguagem da ilha - que opera uma possível imagem da linguagem literária - não pode "estacionar" nem no passado nem no futuro, mas está sempre deslocada, precisando "pavimentar" o caminho a cada nova fala. Outra frase a se destacar é a seguinte: "inventaram uma linguagem que mostra como é o mundo, mas que não permite nomeá-lo”. Mostrar o mundo sem nomeá-lo pressupóe a possibilidade de representação, mas não a de criação, pois nomear algo é participar de sua criação.

No ensaio "Sobre a linguagem em geral e sobre a linguagem do homem", Walter Benjamin escreve que "a essência linguística do homem está no fato de ele nomear as coisas", * ou seja, a nomeação (criação com a linguagem) é própria do humano. "O nome é aquilo através do qual nada mais se comunica, e em que a própria língua se comunica a si mesma, e de modo absoluto".* A língua da ilha não pode nomear porque não pode comunicar-se a si mesma. Situada entre a possibilidade e a impossibilidade de dizer, ocupa a 
posição de resto. Assim como o tempo/espaço habitado pelos moradores da ilha, a nomeação do "núcleo 'duro' das coisas" ${ }^{10}$ deve ser recriada a cada novo ciclo linguístico.

Rafaela Scardino é doutoranda pelo Programa de Pós-Graduação em Letras da Universidade Federal do Espírito Santo (UFES) e desenvolve pesquisa sobre deslocamento na obra do escritor argentino Ricardo Piglia. É autora de Movimentos de demolição: deslocamentos, identidades e literatura (Edufes, 2011) e coorganizadora de $A$ crítica literária: percursos, métodos, exercícios (PPGL/UFES, 2009) e Traços de um outro mapa: literatura contemporânea nas Américas (Edufes, no prelo). E-mail: <rafaelascardino@yahoo.com.br>

${ }^{10}$ KEHL, M. R. "O sexo, a morte, a mãe e o mal”. In: NESTROVSKI, Arthur; SELIGMANN-SILVA, Márcio (orgs.). Catástrofe e representação. São Paulo: Escuta, 2000, p. 138: "De cada experiência, de cada objeto, de cada percepção, fica sempre um resto que não conseguimos simbolizar; o núcleo 'duro' das coisas, que lhes confere independência em relação à linguagem e nos garante, de alguma forma, que o mundo nâo é uma invenção de nosso pensamento". 